\title{
The Effectiveness of the Nimali Variety of Sri Lankan Punica granatum L. Fruit Extracts on Rhabdomyosarcoma (RD) Cells Concerning the Apoptotic Signaling Pathway
}

\author{
Udeshika Yapa Bandara, Chamindri Witharana*, Preethi Soysa
}

\begin{abstract}
Objective: Pomegranate ,a polyphenol-rich fruit, has been considered as one of the ancient fruits with anticancer effect. Cell cycle arrest is considered as an ordinary factor in human cancer, and apoptosis is the frequent drug target. This study aimed to evaluate the effectiveness of the Nimali variety of Sri Lankan Punica granatum L. fruit extracts on rhabdomyosarcoma (RD) cells concerning the apoptotic signaling pathway. Methods: Antiproliferative activity of aqueous extracts of pomegranate peel, pericarp, was assessed using multiple extraction methods (sonication, microwaving, sonication followed by microwaving, keeping in a waterbath, and boiling at $100^{\circ} \mathrm{C}$ ). Total protein content, nitric oxide production, LDH, and caspase- 8 and caspase- 3 activities were analyzed in peel extracts prepared by sonicated or microwave methods. RT-qPCR was performed with intact RNA to explore the apoptotic pathway and gene expression. Results: Peel extracts expressed minimum cell viability in a dose-dependent manner, induced cell death on RD cells. However, sonicated peel extract (SPL) indicated the lowest $\mathrm{IC}_{50}$ of $14.8 \pm 2.2 \mu \mathrm{g} / \mathrm{mL}$ comparative to healthy VERO cells $(>1,000 \mu \mathrm{g} / \mathrm{mL})$. A decrease of nitrite content in the supernatant was visualized in the graph plotted against concentration. Furthermore, SPL upregulated caspase- 8 and caspase- 3 signaling pathways and expression of p21 and p53 genes. Conclusion: The findings highlighted the promising therapeutic potential of SPL to inhibit RD growth and progression and to modulate the caspase- 8 and caspase-3, p53, and p21 dependent pathway.
\end{abstract}

Keywords: Pomegranate- Punica granatum L.- Apoptosis- p53/p21 genes- RT-qPCR- caspase 3- caspase 8- LDH

Asian Pac J Cancer Prev, 23 (2), 501-510

\section{Introduction}

World Health Organization has reported cancer as the second cause of mortality with 9.6 million deaths in 2018. Nearly, $70 \%$ of deaths from cancer are reported in low and middle-income countries (WHO, 2018).

Allopathic treatment is associated with adverse effects and poor efficacy. Due to anticancer activity, phytochemicals are currently practiced as a treatment for cancers . Nearly, $60 \%$ of anticancer agents are synthesized by natural products (Bandara and Witharana, 2018). Pomegranate has been considered as a polyphenol-rich ancient fruit and belongs to Lythraceae family. It can cure a wide range of diseases in folk and ayurvedic medicine. Studies have reported that pomegranate peel, pericarp, juice, seeds, leaves, and bark have antioxidant properties providing numerous health benefits (Amar et al., 2017). It has been revealed that the bound form of ellagic acid is more abundant in pomegranate. Thus, ellagic acid exhibits a wide spectrum of antitumor properties through multiple pathways (Zhang et al., 2014). Similarly, Masci et al., (2016) concluded that polyphenols were susceptible to oxidative degradation extraction conditions can considerably affect the efficiency, stability, and yield of polyphenols thus differing antioxidant activity in pomegranate fruit extracts.

Apoptosis is the programmed cell death, and induction of apoptosis is crucial in cancer treatment as it reduces the proliferation of the malignant cells. Chemotherapeutic agents can be either DNA-damaging agents, antimetabolites, mitotic inhibitors, nucleotide analogs, or inhibitors of topoisomerases (Herr and Debatin, 2001). In therapeutic strategies aiming at killing tumour cells by targeting apoptosis, stability in the activity of pro-apoptotic and anti-apoptotic members of the BCL-2 family induces the release of cytochrome c from the mitochondria, which leads to activation of proteins of the caspase family, as inactive zymogens. Activation of initiator caspases leads to proteolytic activation of downstream effector caspases that cleave specific substrates (García et al., 2012). DNA fragmentation or visualization of fragmented DNA is due to cleavage and 
inactivation of the initiator of caspase-activated DNase. Caspase 3 activation is a common marker in apoptotic cells. Furthermore, the activation of several kinases (p21-activated kinase) and active blebbing are observed in apoptotic cells. Stress stimuli activates the p53 protein, which promotes cell-cycle arrest, and subsequently leads to DNA repair or apoptosis to eliminate malfunctioning cells (Carneiro and El-Deiry, 2020).

Reverse transcription polymerase chain reaction (RT-qPCR) has been identified as the most sensitive and reliable method for detection and quantification of nucleic acids, at the exponential phase, rather than dectection of the end product as conventional PCR methods (Hossain et al., 2019). Detection of melting temperatures is considered as another option for the characterization of products. The melting point is determined by the time at which the double-stranded DNA gets separated (Tm is $50 \%$ of the DNA becomes SS). According to Bandara et al., (2020), Sonicated Sri Lankan pomegranate peel water extract exhibited the highest radical scavenging capacity (RSC), phenol (TPC), and flavonoid contents (FC) (Bandara et al., 2018).

Hence, we attempted this study to elucidate the process of cell death of rhabdomyosarcoma (RD) cells by apoptosis or necrosis using the effect of sonicated Sri Lankan pomegranate (Punica granatum L.) peel powder extract. The purposes of this research were to evaluate the cytotoxic activity of the aqueous extract of Nimali fruit Punica granatum L. on RD cells by using MTT assay, analyze the induction of apoptosis and inhibition of cell cycle besides, and to predict the anticancer mechanism concerning different extraction methods.

\section{Materials and Methods}

\section{Chemicals and solvents}

Sodium bicarbonate, Sodium chloride, ethylenediaminetetraacetic acid (EDTA), Modified Eagle's medium (MEM) (Cat.no. M0769), [3-(4,5-dimethylthiazol2-yl)-2,5-diphenyltetrazolium bromide] (MTT) ( Cat. No:M2128), and Fetal Bovine Serum (FBS) (Cat No: F9665) were purchased from Sigma Chemicals Co. (P.O.Box 14508, St. Louis, MO 63178 USA). Other chemicals were obtained from Sigma-Aldrich Co (St Louis, MO, USA). All chemicals used were in analytical grade. Lactate Dehydrogenase Activity Assay Kit (Sigma-Aldrich, St. Louis, MO; Catalog Number: MAK066) was used in this study. Trizol® reagent was purchased from Life Technologies (Thermo Fisher Scientific,168, MA USA, Cat No: 15596018). Primers were manufactured by Integrated DNA Technologies, Pte. Ltd. and purchased from Avon Pharmo Chem (Pvt.) Ltd. CaspACETM Assay (Colourimetric -3) (Cat No: G7351) and GoTaq ${ }^{\circledR}$ 1-Step RT-qPCR Systems (Cat No: A6020) were purchased from Promega Corporation (2800, Woods Hollow Road, Madison, WI 53711-5399 USA). Colourimetric 8 Assay Kit was purchased from Merck life science (Merck KgaA, Darmstadt, Cat No: APT129).

\section{Plant material}

Sri Lankan Punica granatum L. (Nimali) was obtained from Fruit Research Institute, Department of Agriculture, Kalpitiya, Sri Lanka (January 2017). Plant species were taxonomically identified, and a voucher specimen was deposited in Botany Department, Bandaranayake Memorial Ayurveda Research Institute, Nawinna, Colombo, Sri Lanka (specimen number 2025).

\section{Preparation of pomegranate peel and pericarp extracts}

Pomegranate peel (PL) and pericarp (PC) samples were freeze-dried (Labconco Free Zone Legacy Benchtop Freeze Drier, Model No: $7670530,220 \mathrm{~V})$ at $-40^{\circ} \mathrm{C}$ until constant weight. Lyophilized powder was subjected to selected extraction methods at the following conditions: boiling for 45 minutes, sonication at $50 \mathrm{kHz}, 135 \mathrm{~W}$, for 30 minutes, followed by microwaving at $50 \mathrm{kHz}, 135$ $\mathrm{W}$, for 30 minutes $(2,450 \mathrm{MHz}, 1,050 \mathrm{~W}, 3$ minutes), microwaving at 2,450 MHz, 1,050 W, for 3 minutes, and heating in a water bath at $50^{\circ} \mathrm{C}$, for 20 minutes. Powdered extracts were stored airtight at $-20^{\circ} \mathrm{C}$ to prevent deterioration caused by moisture and microbial growth.

\section{Cell culture}

Human rhabdomyosarcoma cancer cell line (RD) and healthy cell line (VERO - African green monkey) were obtained from Medical Research Institute, Colombo 08, Sri Lanka, and cultured with Minimum Essential Medium (MEM) supplemented with 10\% fetal bovine serum (FBS), L - Glutamine (3\%), 10,000U/mL penicillin \& $10 \mathrm{mg} / \mathrm{mL}$ streptomycin, 7.7\% sodium bicarbonate, and HEPES (1M) in $5 \% \mathrm{CO}_{2}$ incubator (SHEL LAB/Sheldon Manufacturing Inc., Cornelius, OR 97113, USA) at $37^{\circ} \mathrm{C}$ in a humidified atmosphere. Cells in exponential growth were used for assays with FBS-free medium and exposed to extractions in different concentrations $(100 \mu \mathrm{L} /$ well $)$ in 96-well plates. The ethical approval was obtained from the Ethics Review Committee, Faculty of Medicine, University of Colombo, Colombo 08, Sri Lanka (Reference No: EC-16-220).

\section{Cell viability assay}

Cell viability was determined by using MTT cytotoxicity assay at $540 \mathrm{~nm}$ with 96 microplate reader with extracts of PL and PC on RD and VERO cells for $24 \mathrm{~h}, 48 \mathrm{~h}$, and $72 \mathrm{~h}$. Cycloheximide $(0.1 \%, 25 \mu \mathrm{l})$ was considered as positive control and sample was prepared as a concentration series $(2,8,10,15,20,30,60$, and $100 \mu \mathrm{g} / \mathrm{mL}$ ). Percentage cell cytotoxicity was determined according to the following formula,

$$
\% \text { Cytotoxicity }=(A b \text { (control) }-A b(\text { sample })) / A b(\text { control }) * 100
$$

\section{Lactate dehydrogenase (LDH) activity}

Lactate dehydrogenase (LDH) activity of supernatant and lysate of RD cells, after treatment with sonicated and microwaved pomegranate peel extractions, was measured by the LDH Activity Assay Kit (Sigma-Aldrich, St. Louis, MO; Catalog Number: MAK066) and according to the manufacturer's instructions.

\section{Estimation of protein content}

The protein content of the cell lysate was determined by the method suggested by Lowry et al., (1951) and (Oliver 
et al., (1951) followingtreatment with pomegranate peel extractions for $24 \mathrm{~h}$. The calibration curve was plotted with Bovine Serum Albumin (BSA). The percentage protein content of treated cells was calculated as follows.

Protein content\% $=[$ Protein content of treated sample/ Protein content of untreated] $* 100$

\section{Griess nitrite assay for nitric oxide production in cells}

The cell supernatant obtained from the MTT assay was used to assay nitric oxide production in cells. The standard curve was constructed using Sodium nitrite $(0.25-3 \mu \mathrm{g} / \mathrm{ml})$. aThe nitrite content in the supernatant was also determined.

\section{Ethidium bromide and acridine orange (EB/AO) and Giemsa staining}

The apoptosis in RD cells was determine by sonicated peel extract (SPL). Morphological changes were examined using a phase-contrast inverted fluorescence microscope under an ultraviolet (UV) lamp and imaged with a digital imaging system.

\section{DNA fragmentation assay}

The isolation of fragmented DNA was carried out according to the procedure suggested by Kasibhatla et al., in 2006 and by implementing slight modifications. The cells $\left(1 \times 10^{6}\right)$ were seeded in 24 well plates and treated with different concentrations of SPL for $24 \mathrm{~h}$. $1000-k b p$ DNA marker was used as size reference. DNA was photographed by the UVI pro gel documentation system (UVItec UK.)

\section{Caspase 3 activity}

Caspase 3 activity of RD cells was assayed by Colourimetric Assay Kit (Cat No: G7351, Promega Corporation, 2800 Woods Hollow Road, Madison, USA). The cells were seeded in a 96-well plate and treated with selected concentrations $(10,15,20 \mu \mathrm{g} / \mathrm{mL})$ of SPL in triplicates. The activity of caspase 3 (pmol pNA liberated/ hour) was calculated according to the suggested protocol.

\section{Caspase 8 assay}

Caspase 8 activity of RD cancer cells was assayed by colourimetric caspase 8 Assay Kit (Merck KgaA, Darmstadt, CAT NO: APT129). The cells were seeded in a 24-well plate with a density of $1 \times 10^{6}$ cells/well and treated with selected concentrations $(10,15,30 \mu \mathrm{g} /$ $\mathrm{mL})$ of sonicated peel extract (SPL) $(\mathrm{n}=6)$. The activity of caspase 8 (nmol pNA liberated/Hr) was calculated according to the protocol.

\section{Reverse transcription quantitative PCR (RT-qPCR)}

Total RNA was isolated by TRIZOL(Life Technologies) Invitrogen manual extraction. Extracted RNA samples were adequately diluted and quantified by Qubit ${ }^{\circledR}$ RNA HS Assay kit. Extracted RNA was loaded to agarose gel $(1 \%)$, incorporated with Clorox $(3 \%)$, and stained with ethidium bromide $(0.5 \mu \mathrm{g} / \mathrm{mL})$ in $1 \mathrm{X}$ TAE to judge the integrity and overall quality. Primer pairs for $\mathrm{p} 53, \mathrm{p} 21$, and $\beta$ actin were synthesized by Integrated DNA Technologies
(IDT) Pte, Ltd. $\beta$ actin was utilized as an internal reference for $\mathrm{p} 53$ and $\mathrm{p} 21$ expression. The primers of TP53 were as follows: forward, 5'-ATGAGCCGCCTGAGGTTGG-3' and reverse, 5'-CAGCCTGGGCATCCTTGAGT-3'. The primers of TP2 1 were as follows: forward, 5'-TGGCACCTCACCTGCTCTG-3' and reverse, 5'-GTTTGGAGTGGTAGAAATCTGTCAT-3'. The primers of $\beta$ actin were as follows: forward: 5'-ATCGTGCGTGTGACATTAAGGAG-3' and reverse, 5'-AGGAAGGAAGGCTGGAAGAGTG-3'. RT-qPCR analysis was executed using GoTaq ${ }^{\circledR}$ 1-step RT-qPCR kit (Cat No: A6020, Promega Corporation, 2800 Woods Hollow Road, Madison, USA. $\beta$-actin was used as the housekeeping gene, which is inherent to the cell cytoskeleton. Culture samples with selected concentrations of $1 / 2 \mathrm{IC}_{50}, \mathrm{IC}_{50}$, and $2 \mathrm{IC}_{50}$ were used with this endogenous control. The relative expression of TP2 1 and TP53 was figured by the $2^{-\Delta \Delta \mathrm{Ct}}$ method applying the Ct values obtained (Livak and Schmittgen, 2001).

$\Delta \Delta \mathrm{Ct}=[\mathrm{Ct}$ (target, treated) $-\mathrm{Ct}$ (ref, treated) $]-$ [Ct (target, untreated)-Ct (ref, untreated)]

(3)

\section{Statistical analysis}

Data were presented as mean $\pm \mathrm{SD}(\mathrm{n}=6)$, except RTqPCR $(n=3) . I_{50}$ values were determined from either linear or logarithmic dose-response curves. The viability of cells with effect from different extraction methods was compared and assessed by unpaired t-test (Microsoft Excel, 2010). P values $<0.05$ were considered significant. The graphs of the RT-qPCR were plotted with the RotorGene Q series software.

\section{Results}

Determination of antiproliferative activity of $P L$ and $P C$ extracts

The highest yield of the PL (38\%) and PC $(24 \%)$ extracts was obtained for sonicated extract. Dose-dependent antiproliferative activity exhibited all the extracts. Percentage viability at $50 \%\left(\mathrm{IC}_{50}\right)$ of the PL and PC samples is depicted in Figure 1. The lowest cell viability was represented with the sonication method for PL $(14.8 \pm 2.2 \mu \mathrm{g} / \mathrm{mL})$ and $\mathrm{PC}(30 \pm 0.9 \mu \mathrm{g} / \mathrm{mL})$ on RD cells after 24,48 , and 72 hours of exposure. PL extracts exhibited higher antiproliferative activity compared to PC extracts. A statistical significance $(<0.05)$ was observed in pomegranate PL extract with respect to $\mathrm{M}$, $\mathrm{MS}, \mathrm{B}$, and $\mathrm{W}$ extractions compared to the $\mathrm{S}$ method. No significant changes was observed with respect to MS and W extractions compared to the S method, while $\mathrm{M}$ and $\mathrm{B}$ extractions of $\mathrm{PC}$ indicated a significant difference $(<0.05)$. Furthermore, $\mathrm{RD}$ cells responded more effectively towards decreasing cell viability compared to VERO cells. Distinctly elevated cell viability was denoted with peel extracts on VERO cells $(>1,000 \mu \mathrm{g} /$ $\mathrm{mL} \mathrm{IC}_{50}$ ) after 24 hours, indicating less toxicity towards healthy cells. Therefore, apoptotic activity was performed with SPL extract. Figure 2 depictes the morphological changes, shrunken appearance, condensed cytoplasm, 

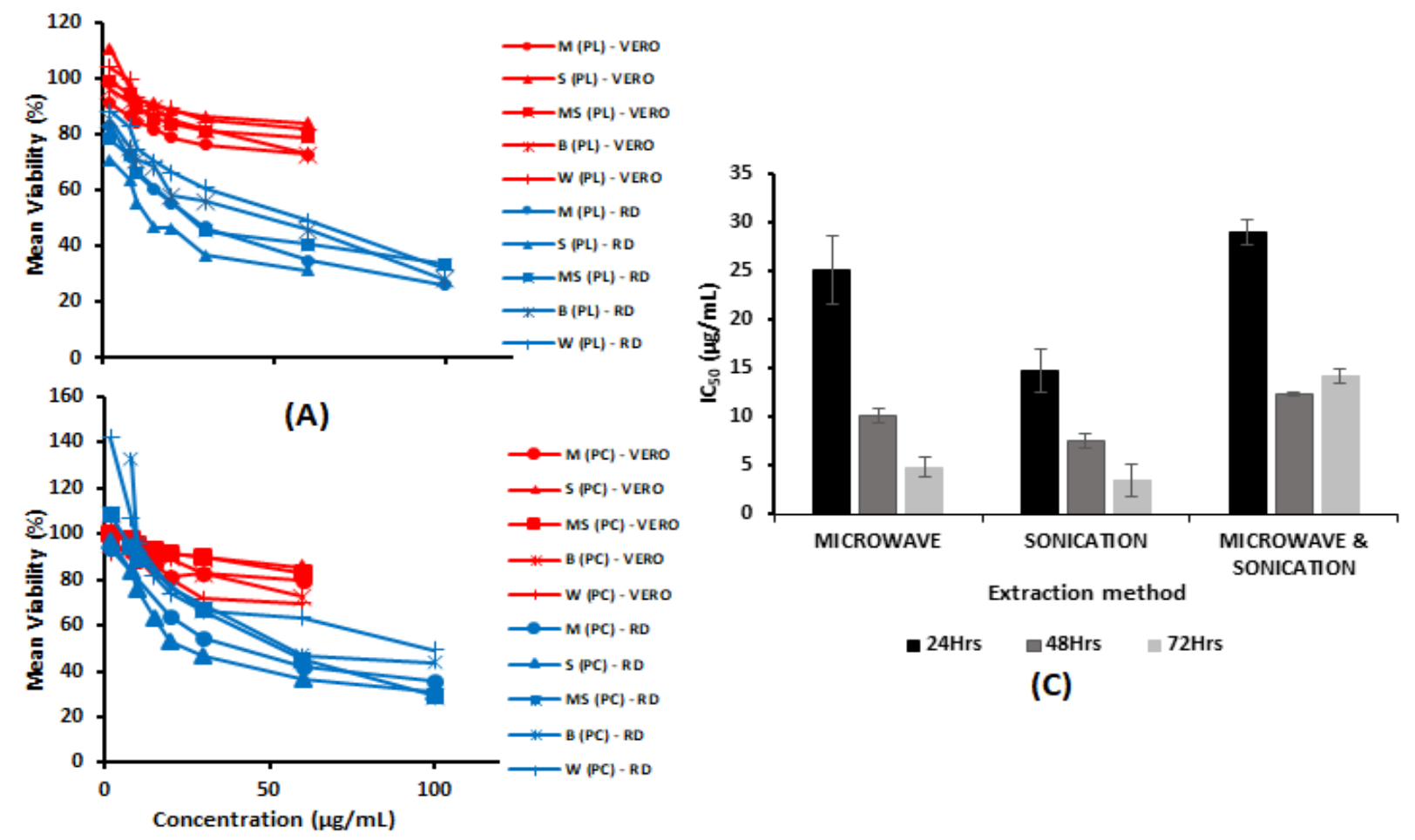

(C)

(B)

Figure 1. Mean \% Viability of RD Cancer Cells Compared to VERO Healthy Cells with Effect of Concentration of Punica granatum L. (A) Peel (B) Pericarp Extracts with MTT Cytotoxicity Assay after 24Hrs. (C) Concentration of Punica granatum L. PL extracts with at $50 \%$ viability $\left(\mathrm{IC}_{50}\right)$ compared to extraction methods with MTT cytotoxicity assay after $24 \mathrm{Hrs}, 48 \mathrm{Hrs}$, and $72 \mathrm{Hrs}$ incubation with RD cells. Data represent the mean $\pm \mathrm{SD}(\mathrm{n}=6)$. Microwave (M); Sonication (S); Microwave \& Sonication (MS); Boiling (B); Waterbath (W)

and membrane blebbing of RD and VERO cells treated with SPL extract.
Ethidium bromide/acridine orange (EB/AO) and Giemsa staining

Following EB/AO and giemsa staining, cells treated

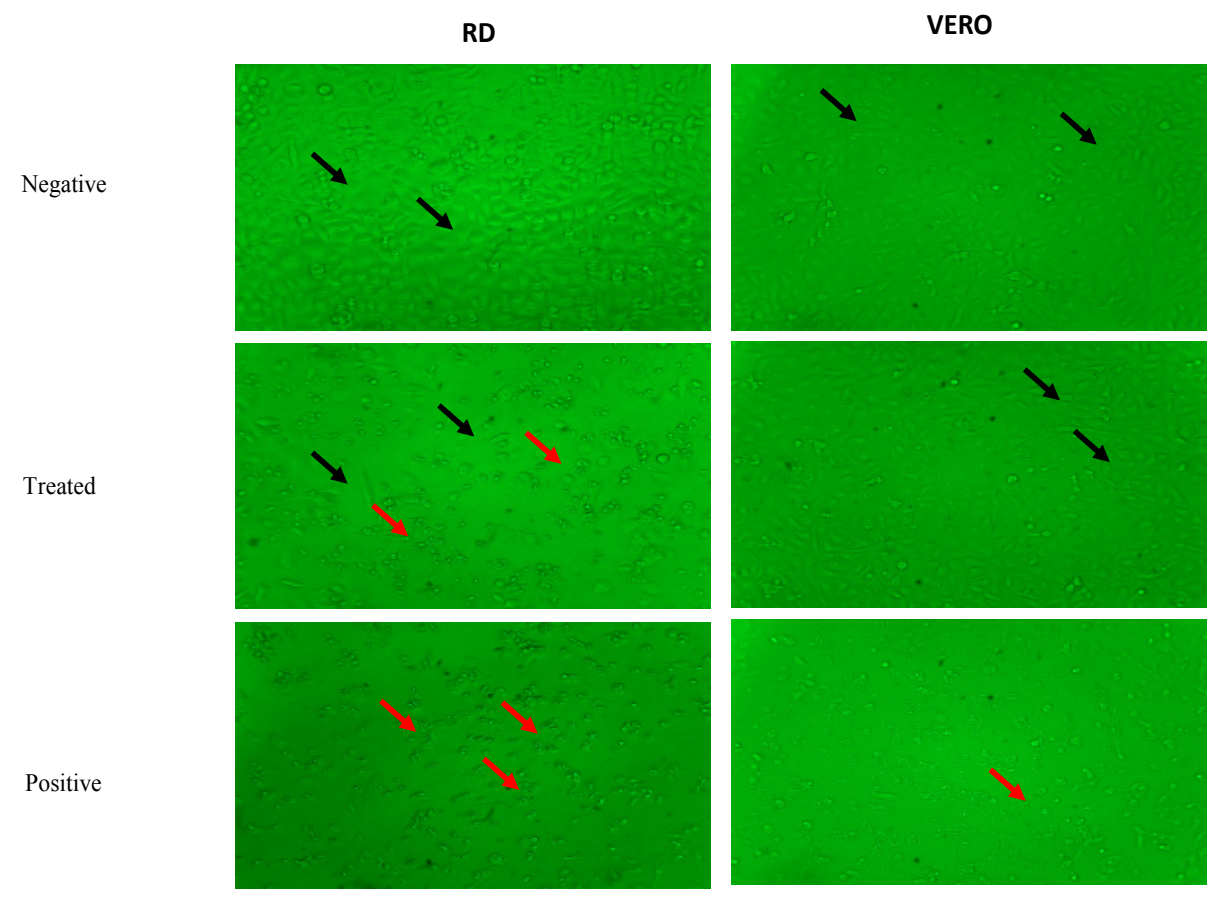

Figure 2. Morphological Changes of RD, and VERO Cells after 24Hrs Exposure of SPL Extract with Respective IC ${ }_{50}$ Values and Cycloheximide (Positive Control) under Light Microscopy (20X). (Black arrow - healthy spindle shape cells, Red arrow - dead and shrunken cells due to the treatment of SPL extract 


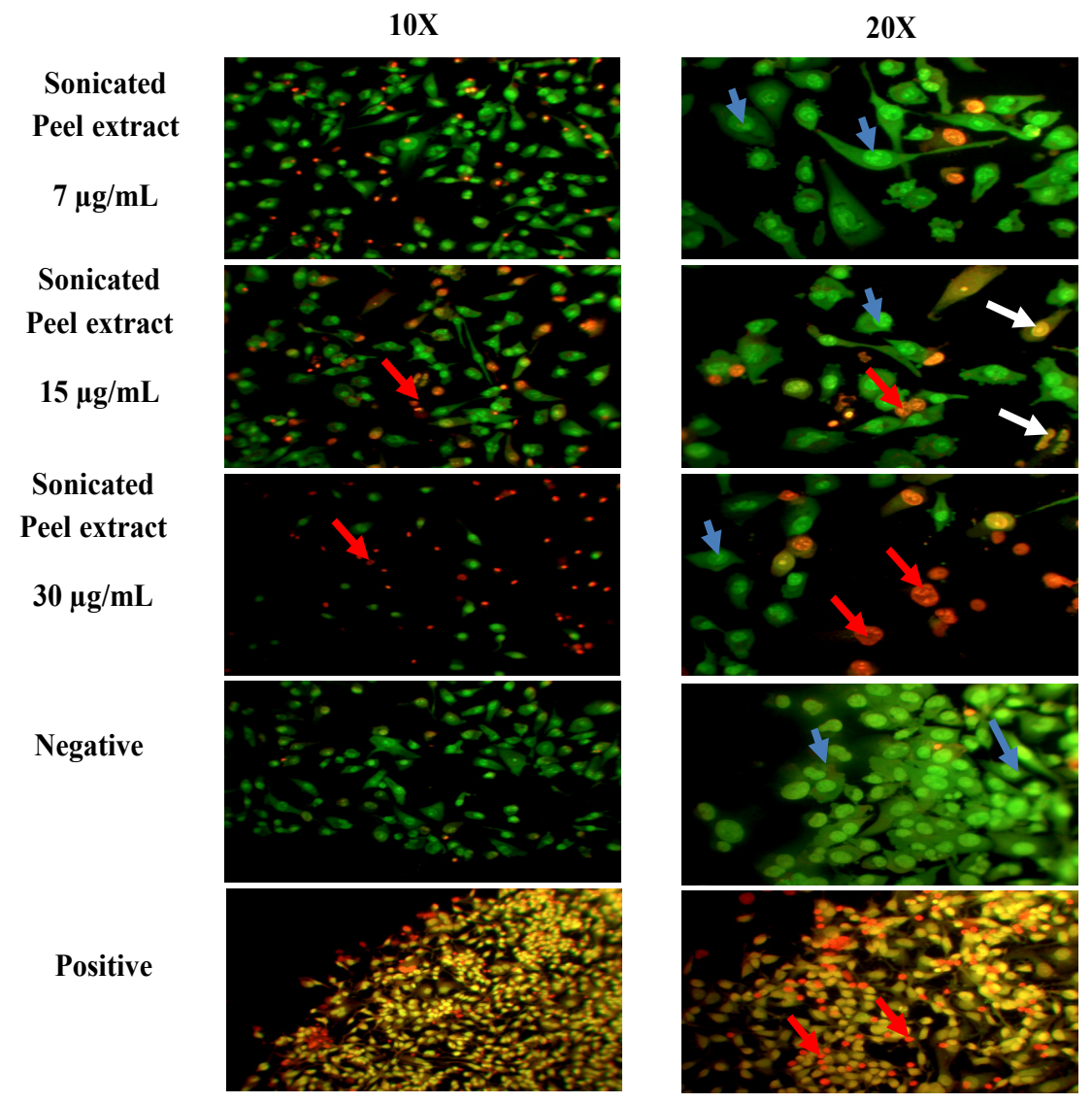

Figure 3. Morphological Changes of Ethidium Bromide/Acridine Orange Stained RD Cells (Representative Images from $n=6)$. Blue arrows - live cells; White arrows - early apoptotic cells with blebbing and Red arrows - late apoptotic cells.

with SPL caused typical apoptotic morphological changes, including chromatin condensation, membrane blebbing, and fragmented nuclei in RD cells in contrast to the controls (untreated cells). Cycloheximide $(50 \mu \mathrm{g} / \mathrm{mL})$ treated positive control cells were presented with yellow to red colour, reflecting apoptotic features following EB/ AO staining (Figure 3).

After giemsa staining, RD cells treated with SPL
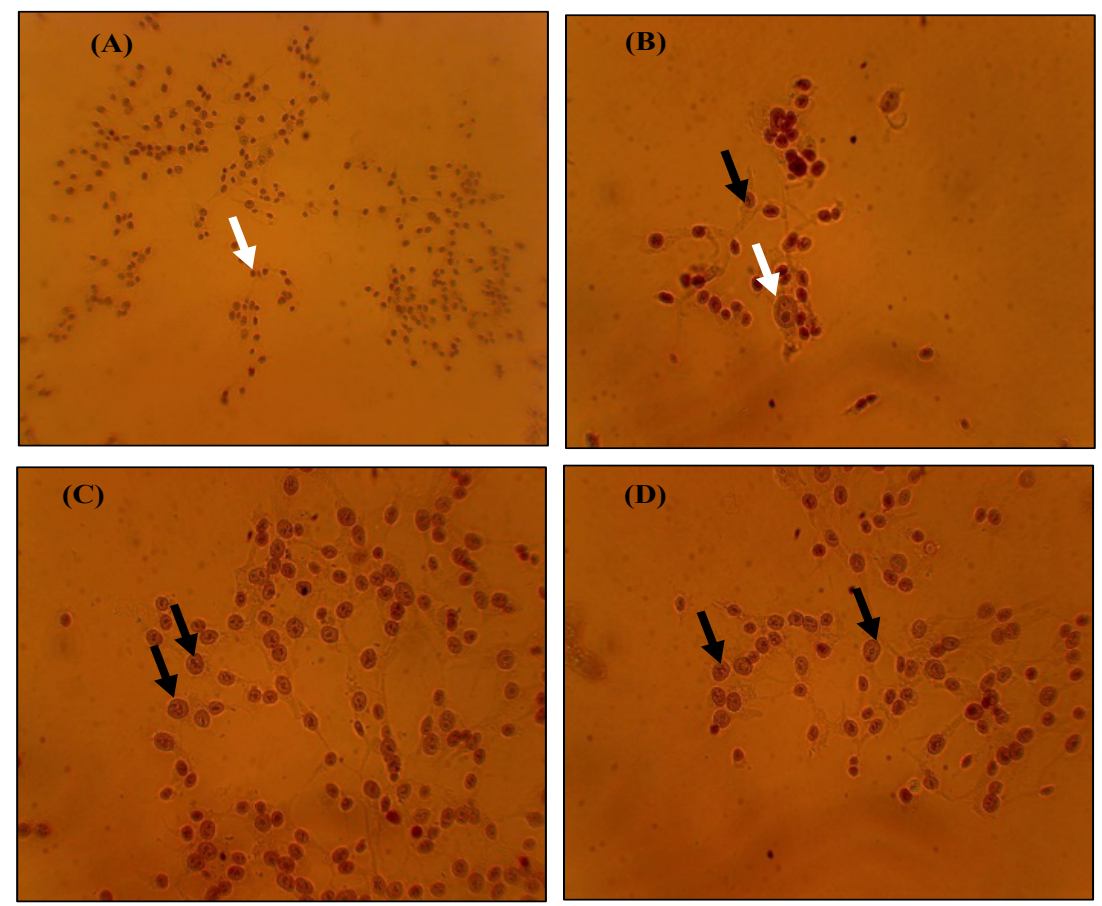

Figure 4. Images of Giemsa-Stained RD Cells (representative images from n=6). (A) Negative control, (B) Positive control, (C) and (D) were $15,30 \mu \mathrm{g} / \mathrm{mL}$ concentrations of SPL respectively. White arrows - live cells; black arrows - cells with apoptotic changes. 
(+) ve $\quad(-)$ ve $\quad$ Ladder $\quad 30 \mu \mathrm{g} / \mathrm{mL} \quad 15 \mu \mathrm{g} / \mathrm{mL} \quad 7 \mu \mathrm{g} / \mathrm{mL}$

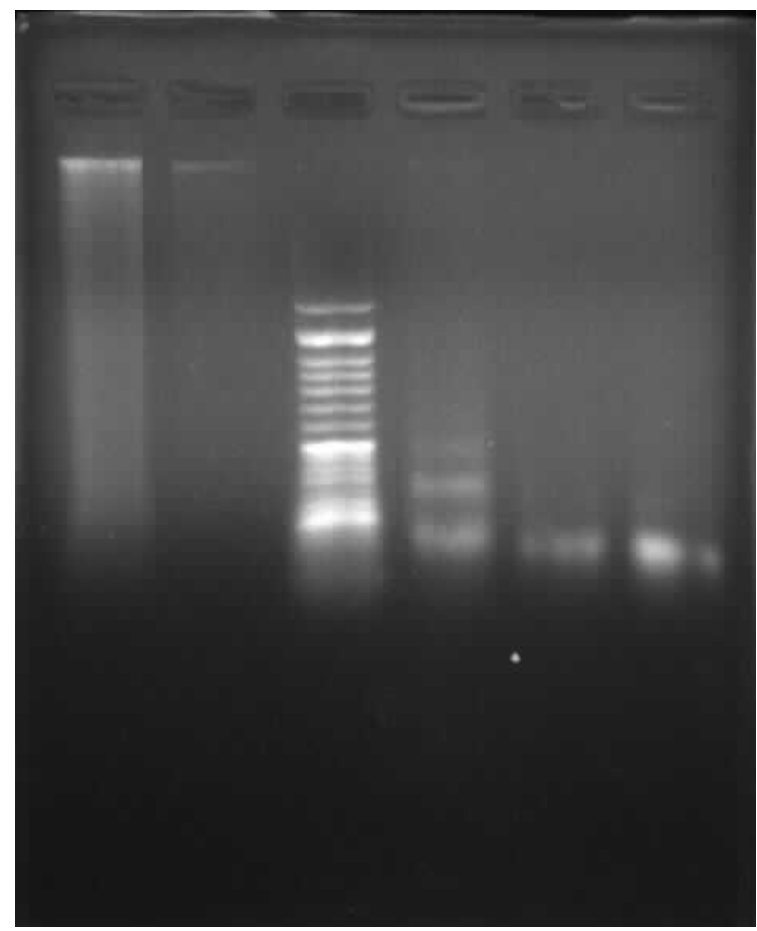

Figure 5. DNA Fragmentation for RD Cells Treated with SPL Extract $(n=6)$ after $24 \mathrm{Hrs}(1.2 \%$ agarose $)$ were visualized with cellular shrinkage, chromatin condensation, accumulation, and nuclear fragmentation with intact cell membrane (Figure 4).

DNA fragmentation assay

DNA fragmentation with a smear pattern was observed in RD cells exposed to SPL for $24 \mathrm{~h}$. Detection of DNA fragments is an integral part of apoptosis. Untreated control cells showed no evidence of DNA fragmentation, while the positive control cycloheximide at $50 \mu \mathrm{g} / \mathrm{mL}$ showed DNA fragmentation (Figure 5).

Determination of total protein content, Nitric Oxide production, released LDH concentration, and caspase 3 as well as caspase-8 enzyme activities

The protein content of lysates was determined in $\mathrm{S}$ and M PL extractions after $24 \mathrm{~h}$ exposure. A reduction was found in total protein content in RD cells treated with S and M PL extractions in a dose-dependent manner, predicting that the S and M PL extractions may induce an inhibitory mechanism of protein synthesis in RD cancer cells by causing cell death (Figure 6A). A decrease of nitrite content in the supernatant of S, M, and PL extracts was visualized in the graph plotted against concentration (Figure 6B). NO content was determined by using the calibration curve plotted between absorbance and the concentration of sodium nitrite.

Leakage of cytoplasmic located enzyme LDH into

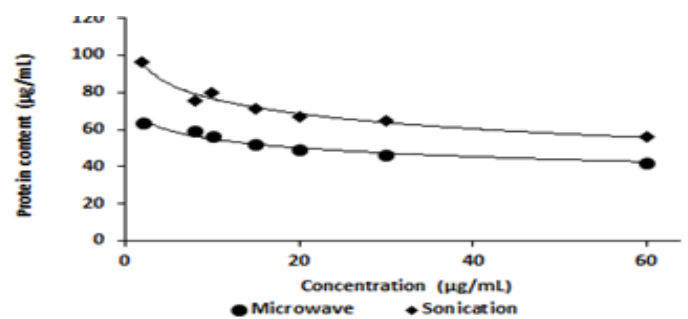

(A)

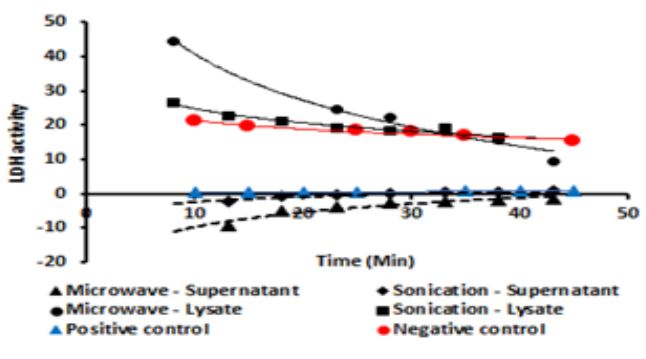

(C)

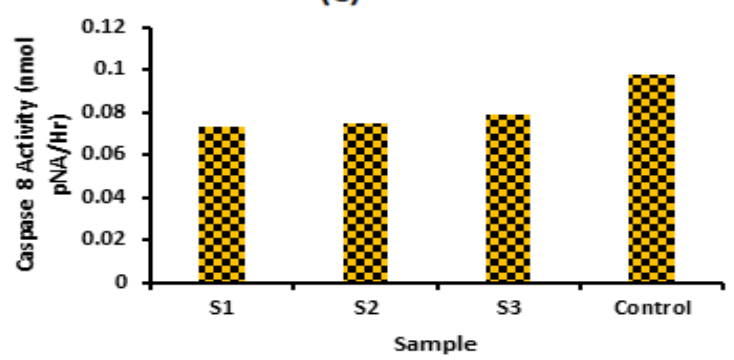

(E)

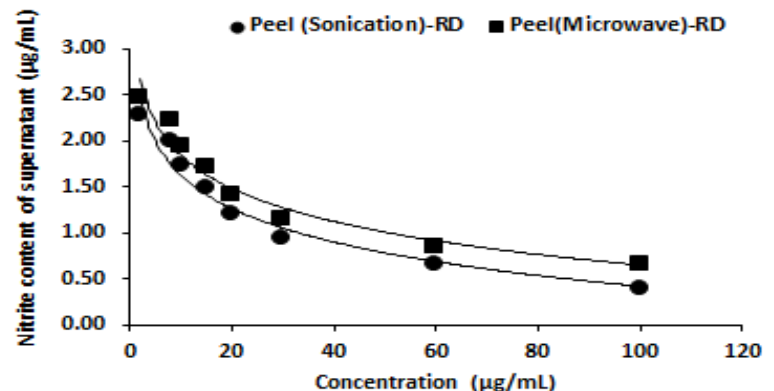

(B)

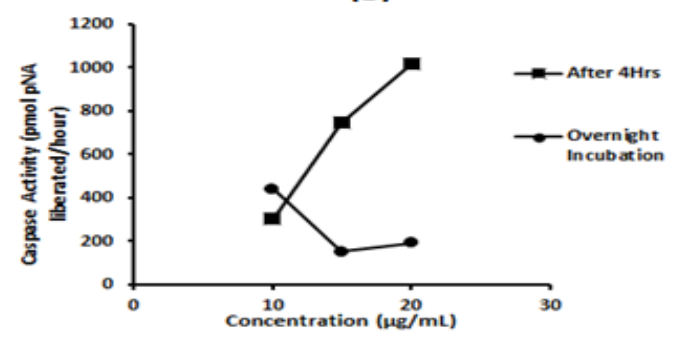

(D)

Figure 6. (A) Effect of S and M extractions of pomegranate PL at different concentrations on total protein (B) NO production in RD cell lysate. (C) Dose dependent LDH concentration after incubation with S and M extractions of pomegranate PL on RD cells. (D) Caspase-3 activity after treatment with SPL at different concentrations on RD cells for 4Hrs and 24Hrs. (E) Caspase-8 activity after treatment with SPL at different concentrations $(10,15,30 \mu \mathrm{g} / \mathrm{mL}) \mathrm{on}$ $\mathrm{RD}$ cells for $2 \mathrm{Hrs}$. Data represent the mean $\pm \mathrm{SD}(\mathrm{n}=6)$. 


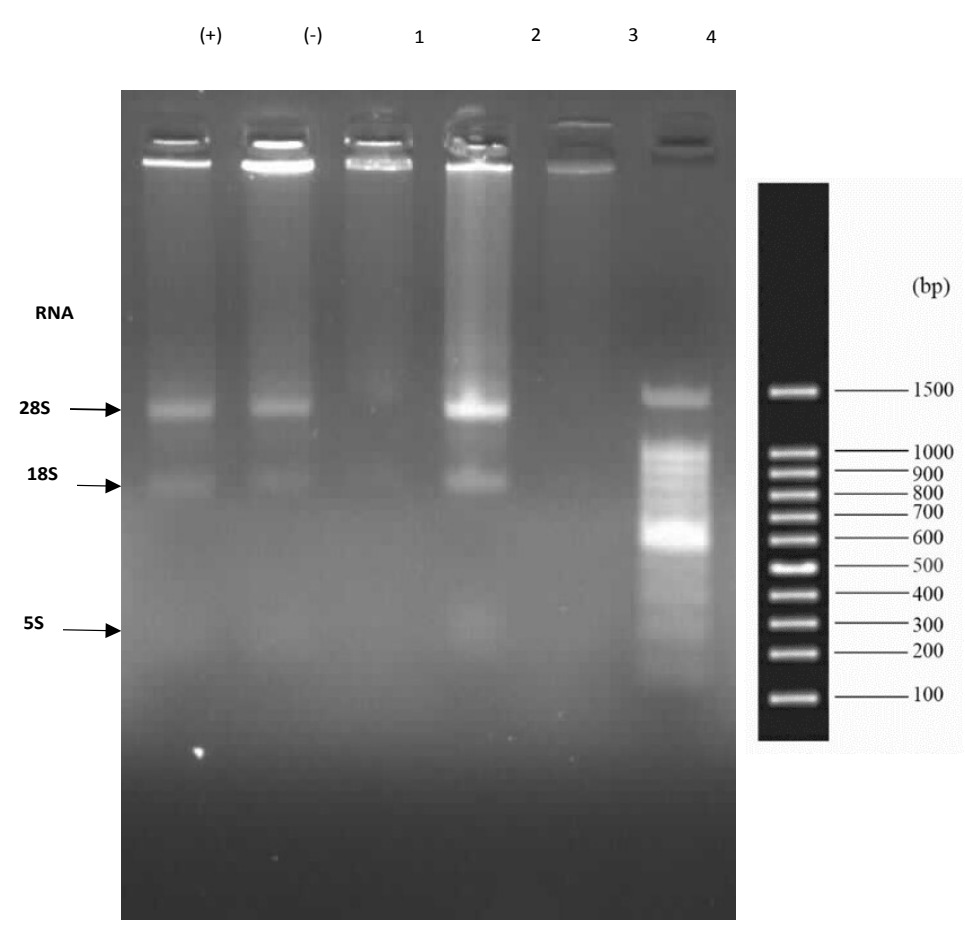

Figure 7. Agarose Gel Photograph of RNA Extraction of RD Cells Treated with SPL after 24Hrs (1.0\% Agarose Gel Treated with Clorox). $1=10 \mu \mathrm{g} / \mathrm{mL}, 2=15 \mu \mathrm{g} / \mathrm{mL}, 3=20 \mu \mathrm{g} / \mathrm{mL}$ SPL concentrations; $4=$ DNA ladder (100bp)

the extracellular medium is usually measured in lactate dehydrogenase (LDH) assay. In the present study, a dose-dependent increase in LDH release was observed following increase of supernatants concentrations and decrease of lysates of two extracts (Figure 6C) on RD cells. Caspase 3 enzyme activity was induced after 4

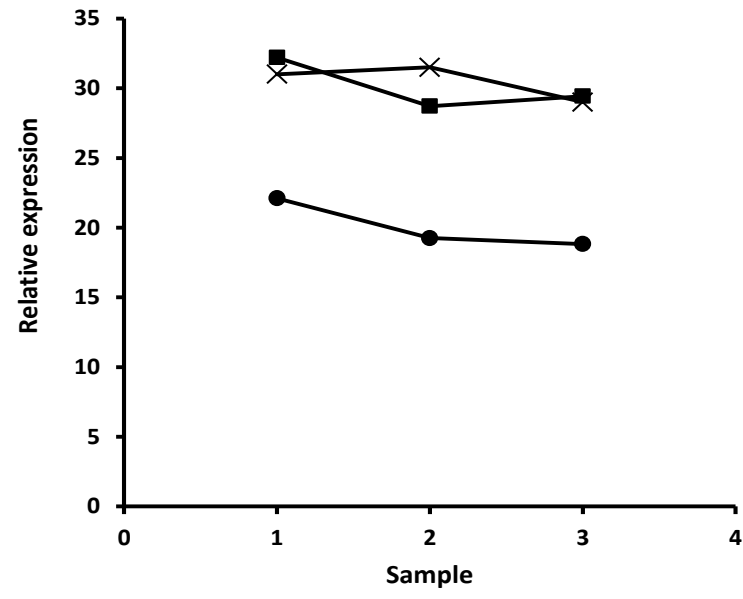

$\rightarrow-p 21$ gene

$\rightarrow$ p53 gene

$\rightarrow$ Reference gene

A $\mathrm{h}$ incubation with the concentration, while it reduced during overnight incubation (Figure 6D). Further, the findings of this study revealed that Sonicated peel extract exerted higher cytotoxicity against RD cells than Microwave extract. A fold increase in caspase- 8 activity was determined by comparing the optical density (OD) of

(a)
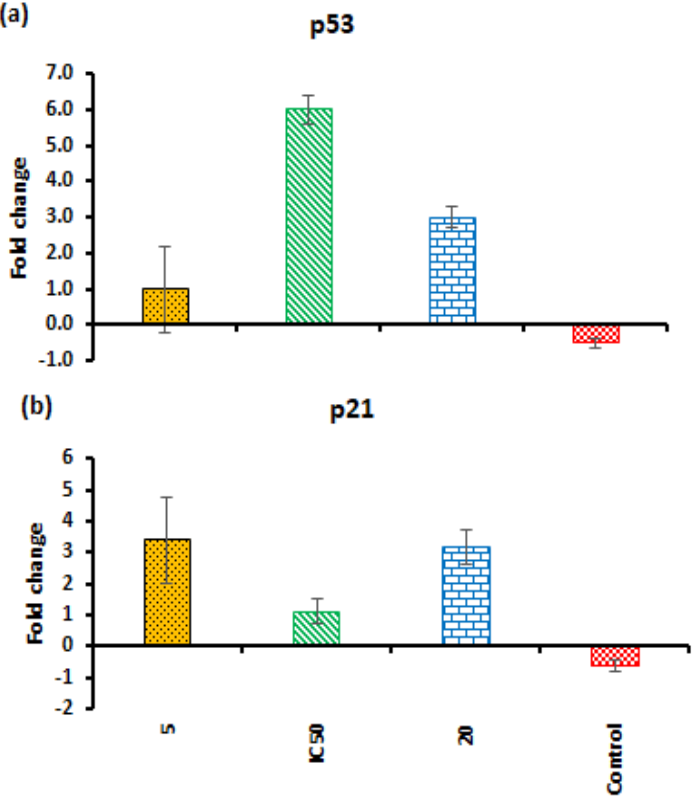

Concentration $(\mu \mathrm{g} / \mathrm{mL})$

\section{B}

Figure 8. (A) Comparison of expression of p21 and p53 genes reference to $\beta$ actin, reference gene. $(1=5 \mu \mathrm{g} / \mathrm{mL}$, $2=15 \mu \mathrm{g} / \mathrm{mL}, 3=20 \mu \mathrm{g} / \mathrm{mL}$ ). (B) SPL extract effects on p21 and p53 mRNA levels in RD cells after treatment with $5 \mu \mathrm{g} /$ $\mathrm{mL}, 15 \mu \mathrm{g} / \mathrm{mL}\left(\mathrm{IC}_{5}\right)$, and $20 \mu \mathrm{g} / \mathrm{mL}$ for $24 \mathrm{Hrs}$. The relative quantification of the target gene was done by the $\Delta \Delta \mathrm{Ct}$ method using the Rotor-Gene Q Series software. Triplicate samples were analyzed. Data represent the mean \pm SD. 
the induced apoptotic sample with the uninduced control after $2 \mathrm{~h}$ incubation. Concentration-dependent caspase 8 activity was found in RD cells (Figure 6E).

\section{Real-Time Quantitative PCR (RT-qPCR)}

The extracted RNA was composed of $28 \mathrm{~S}, 18 \mathrm{~S}$, and 5S ribosomal components (Figure 7). SPL sample of $10 \mu \mathrm{g} / \mathrm{mL}$ was composed with $61.01 \mathrm{ng} / \mathrm{mL}$ of RNA, while positive control was composed with $59.77 \mathrm{ng} / \mathrm{mL}$ of RNA and negative control with $975.02 \mathrm{ng} / \mathrm{mL}$ of of RNA consecutively. RT-qPCR was applied to analyze mRNA levels of apoptotic and cell cycle-related genes in RD cancer cells exposed to SPL at the concentrations of $5 \mu \mathrm{g} / \mathrm{mL}, 15 \mu \mathrm{g} / \mathrm{mL}\left(\mathrm{IC}_{50}\right)$, and $20 \mu \mathrm{g} / \mathrm{mL}$ for $24 \mathrm{~h}$. The expression of the $p 21$ gene in the treated RD cells was found to be dramatically up regulated by $3.38,1.1$, and 3.16 -fold at the concentrations of $5 \mu \mathrm{g} / \mathrm{mL}, 15 \mu \mathrm{g} / \mathrm{mL}$ $\left(\mathrm{IC}_{50}\right)$, and $20 \mu \mathrm{g} / \mathrm{mL}$, respectively, while the $p 53$ gene expression remarkably up regulated by 1.0, 6.0, and 3.0fold, respectively (Figure 8). Treatment of the SPL extract up regulated the expression of the $p 21$ gene by 2.5 -fold and 53 by 3.3 fold compared to controls and housekeeping gene. Hence, the SPL ensued apoptosis via p53-dependent caspase pathway.

\section{Discussion}

One of the leading causes of death worldwide remains cancer. Various therapies have been used, including natural products. These natural plant derived compounds provide a novel treatment with fewer side effects and even sometimes better efficacy.

The secondary metabolites in medicinal plants enhance the potent activity for curing various diseases. Their adaptogenic, antioxidant, and anticancer activities have been stimulated essentially with phenolic compounds, tannins, and flavonoids. Pomegranate fruit is rich in potent antioxidants, tannins, and phenolics (ellagic tannins, ellagic acid, and gallic acid). Although pomegranate peel comprises of polyphenols and constitutes about $50 \%$ of the total fruit weight, it is discarded as waste. In this study, it was found that antiproliferative activity of pomegranate peel against RD cells was higher than pericarp irrespective of the method of extractions. Previous studies revealed that Thelephora ganbajun mushroom, Hibiscus cannabinus oil, and propolis had more efficacy against cytotoxicity when they were extracted through ultrasound-assisted extraction method compared to other conventional extraction methods (i.e. maceration, soxhlet extraction, and supercritical carbon dioxide fluid extraction) ( $\mathrm{Xu}$ et al., 2016; Yazan et al., 2011;Khacha-ananda et al., 2016). Previously, a positive correlation was determined between antioxidant capacity and total phenolic content of parts of Sri Lankan pomegranate fruit. It was also found thatthe highest total phenolic content was presented in the pomegranate peel. Faster kinetics, higher extraction yield , and preserving thermolabile compounds were recognized as the benefits of the sonication method (Bandara et al., 2018).

Recent studies have revealed that polyphenols are the main phytochemicals involving in the antiproliferative activity of plants (Li et al., 2013). Polyphenols, mainly ellagitannins and ellagic acid, which are more abundant in pomegranate peels are responsible for such higher antiproliferative activity (Masci et al., 2016). Pomegranate juice has been shown to have a higher antiproliferative, apoptotic, and antioxidant activity than the purified polyphenols, which suggests synergistic and multifactorial effects of multiple compounds (Seeram et al., 2008). The cellular stress conditions can interfere with signaling pathways in protein synthesis (Jeffrey et al., 2002). Literature suggests that $\mathrm{LDH}$ is a more reliable and accurate marker of cytotoxicity since damaged cells are fragmented completely during prolonged incubation with substances. We examined the effect of SPL on the cascade of caspases that were crucial initiators or effectors in the cell death pathways. Further decisions were made by DNA fragmentation assay, indicating a unique ladder banding pattern or slight smear. Activated caspases cleave inhibitor of caspase-activated DNase (ICAD) promoted the release of active caspase-activated DNase (CAD) according to a previous study (Jacobson et al., 1997). The activated CAD then cleaves the nuclear scaffold and cytoskeleton, further oligonucleosomal DNA at the inter-nucleosomal linker sites yielding DNA fragments in multiples of 180 base pairs (Lavrik et al., 2005). One of the key endpoints for understanding the molecular basis of carcinogenesis is the quantitation of gene expression. Due to a very low concentration of RNA, Qubit Fluorometer was performed, as an alternate fluorescence-based detection method, in this study.

Apoptosis can be induced by p53 protein, which is a transcription factor, through regulating the pro-apoptotic and anti-apoptotic genes. The p53 can promote cell death via its tumor-suppressive function (Clemens et al., 2002). Tumor suppressor gene p53 is involved in G1 arrest and apoptosis. It acts as a transcription factor to induce the expression of $\mathrm{p} 21$. The p21 acts as a cell cycle regulator by arresting cells at G1 and G2 phases. The p21 protein is known as cyclin-dependent kinase inhibitor 1A (CDKN1A) and binds tightly to complexes of cyclins and CDKs, inhibiting their function. The $p 21$ gene is localized on chromosome $6 \mathrm{p} 21.2$, comprising of 3 exons and 2 introns, and encodes the $\mathrm{p} 21$ protein. Hence, induction of p21 arrests the cell cycle in the G1 phase and mediates the function of $\mathrm{p} 53$ in preventing the division of DNA-damaged cells. The most mutated protein in carcinogenesis, p53 induces expression of $\mathrm{p} 21$ in response to cellular stress, such as DNA damage or oxidative stress (Sivonova et al., 2015). Mutation or deletion of p53 is strongly linked with tumor progression and metastasis. The $\mathrm{p} 21$ is important in apoptosis through p53-dependent and p53-independent pathways. Growth and the viability of prostate cancer were suppressed by pomegranate extract through the cki-cyclin-cdk network by upregulating p21 and p27 at G1 phase cell cycle arrest, independent of p53 (Seo et al., 2003).

Pomegranate fruit extract could significantly inhibited lung cancer with a dose-dependent manner, resulting in an induction of WAF1/p21 and KIP1/p27 and reduction of protein expression of cyclins D1, D2, E, cyclindependent kinase (cdk) 2, cdk4, and cdk6 presented with 
a cell cycle arrest in G0 /G1 phase (Panth et al., 2017). Pomegranate peel extract is rich in phenolic acids, urosolic acid, $\alpha$-tocopherol, ellagic acid, quercetin, ellagitannins, luteolin, apigenin, gallic acid, p-hydroxybenzoic acid, chlorogenic acid, and caffeic acid, leading to its antitumor activity (Bassiri-Jahromi, 2018). The cascade pathway is achieved through inactivation of NF-B, a decrease in fatty acid synthase activity and tumor necrosis factor, increase of caspase activities, and upregulation of p21 and p53 expressions (Moghazy and Khader, 2019).

Scavenging of free radicals, induction of enzymes involved in the metabolism of xenobiotics, regulation of gene expression, modulation of cellular signaling pathways including DNA damage repair, cell proliferation, and apoptosis were some reported anticancer properties of phenolic acids (Rosa et al., 2016).

According to Asmaa et al., (2015), p53 and p21 were upregulated in K562 cells by 1.3 and 8.3 times, respectively, following treatment with pomegranate peel extract. To data, SPL treatment amplified the overall expression of the $p 21$ gene by 2.5 fold and p53 by 3.3 fold compared to negative controls and housekeeping gene. According to our findings, SPL extract significantly inhibited rhabdomyosarcoma in a dose-dependent manner, resulting in an induction of p21 and reduction of protein expression of cyclin-dependent kinases presented with a cell cycle arrest in G0/G1 phase via p53 dependentpathway, and ultimately leading to apoptosis.

In conclusion, our data suggested that apoptotic action of SPL on RD cells may be mediated in part through interaction with caspase 3 and caspase 8 pathways. We also found that polyphenolic substances presented in SPL individually or synergistically affected the apoptosis mechanism in RD cells with the least effect on VERO healthy cells. These findings may be helpful for the development of novel chemotherapeutic and chemopreventive agents as a treatment for rhabdomyosarcoma cancer in the future. Future studies are recommened to study the efficacy of this intervention on human samples.

\section{Author Contribution Statement}

Designing the project, data interpretation, and revising the manuscript were carried out by Witharana C. and Soysa P. All the experimental work, data analysis, and drafting of the manuscript were carried out by Bandara U.Y. All authors read and approved the final manuscript.

\section{Acknowledgments}

The authors are thankful of Dr. Janaki Abeynayake, Medical Research Institute, Colombo 08, Sri Lanka for providing the RD cell line. We are also thankful of the staff of the Department of Botany, Bandaranayake Memorial Ayurvedic Research Institute, Nawinna, Colombo, Sri Lanka for the identification of the plant. We acknowledge the cooperation of the technical staff of the Department of Biochemistry \& Molecular Biology, Faculty of Medicine, University of Colombo.

\section{Funding statement}

Financial support for designing the study (purchasing consumables and chemicals) and collection of samples was provided by the Faculty of Medicine, University of Colombo, Colombo 08, Sri Lanka [AP/3/2/2016/SG/11].

\section{Ethical Approval}

Ethical approval was obtained by the Ethics Review Committee, Faculty of Medicine, University of Colombo (Reference No: EC-16-220).

\section{Availability of data}

The data used to support the findings of this study are included in the article.

\section{Conflicts of Interest}

The authors declare no conflict of interest.

\section{References}

Amar Y, Meddah B, Bonacorsi I, et al (2017). Phytochemicals, antioxidant and antiproliferative properties of rosmarinus officinalis L on U937 and CaCo-2 cells. Iran J Pharm Res, 16, 315-27.

Bandara UY, Witharana C, Soysa P (2018). Medicinal Herbs as a treatment for breast carcinoma. Int J Herb Med, 6, 5-9.

Bassiri-Jahromi S (2018). Punica granatum (Pomegranate) activity in health promotion and cancer prevention. Oncology Reviews, 12(1), 1-7.

Carneiro BA and El-Deiry WS (2020). Targeting apoptosis in cancer therapy. Nat Rev Clin Oncol, 2020.

Schmitt CA, Fridman JS, Yang M, et al (2002). Dissecting p53 tumor suppressor functions in vivo. Cancer Cell, 1, 289-98.

Herr I, Debatin KM (2001). Cellular stress response and apoptosis in cancer therapy. Blood, 98, 2603-14.

Hossain MS, Ahmed R, Haque MS, Alam MM, Islam MS (2019). Identification and validation of reference genes for real-time quantitative RT-PCR analysis in jute. $\mathrm{BMC} \mathrm{Mol}$ Biol, 20, 1-13.

Jacobson MD, Weil M, Raff MC (1997). Programmed cell death in animal development. Cell, 88, 347-54.

Jeffrey IW, Bushell M, Tilleray VJ, Morley S, Clemens MJ (2002). Inhibition of protein synthesis in apoptosis: Differential requirements by the tumor necrosis factor $\alpha$ family and a DNA-damaging agent for caspases and the double-stranded RNA-dependent protein kinase. Cancer Res, 62, 2272-80.

Khacha-ananda S, Tragoolpua K, Chantawannakul P (2016). Antioxidant and anti-cancer cell proliferation activity of propolis extracts from two extraction methods antioxidant and anti-cancer cell proliferation activity of propolis extracts from two extraction methods. Asian Pac J Cancer Prev, 14, 6991-5.

Lavrik IN, Golks A, Krammer PH,et al (2005). Caspases: pharmacological manipulation of cell death Find the latest version : Review series Caspases: pharmacological manipulation of cell death. J Clin Invest, 115, 2665-72.

Li Fang, Li Sha, Li Hua-Bin, et al (2013). Antiproliferative activity of peels, pulps and seeds of 61 fruits. J Functional Foods, 5, 1298-309.

Livak KJ, Schmittgen TD (2001). Analysis of relative gene expression data using real-time quantitative PCR and the $2^{-\Delta \Delta C T}$ method. Methods, 25, 402-8.

García MA, Carrasco E, Ramírez AGJ, et al (2012). Apoptosis as a therapeutic target in cancer and cancer stem cells: novel 
strategies and futures perspectives. Apoptosis Med, 2.

Masci A, Coccia A, Lendaro E, et al (2016). Evaluation of different extraction methods from pomegranate whole fruit or peels and the antioxidant and antiproliferative activity of the polyphenolic fraction. Food Chem, 202.

Moghazy AM, Khader MS (2019). Antitumor and Antimicrobial activities of pomegranate (Punica granatum) dried powder peel in vitro. Curr Sci Int, 2019, 764-75.

Lowry OH, Rosebrough NJ, Farr AL, Ra RJ (1951). Protein Measurement with the Folin Phenol Reagent. J Biol Chem, 193, 265-75.

Panth N, Manandhar B, Paudel KR (2017). Anticancer activity of Punica granatum (Pomegranate): A Review. Phytotherapy Res, 31, 568-78.

Rosa LS, Silva NJA, Soares NCP, M. M. T. A. (2016). Anticancer Properties of Phenolic Acids in Colon Cancer - A Review. J Nutr Food Sci, 06.

Seeram NP, Aviram M, Zhang Y, et al (2008). Comparison of antioxidant potency of commonly consumed polyphenolrich beverages in the United States. J Agricul Food Chem, 56, 1415-22.

Seo YH, Joo YE, Choi SK, et al (2003). Prognostic significance of p21 and p53 expression in gastric cancer. Korean J Int Med, 18, 98-103.

Sivonova MK, Vilchova M, Kliment J, et al (2015). Association of $\mathrm{p} 53$ and $\mathrm{p} 21$ polymorphisms with prostate cancer. Biomed Rep, 3, 707-14.

WHO (2018). Cancer 12. Cancer, (September 2018), 2018.

Xu DP, Zheng J, Zhou Y, et al (2016). Extraction of natural antioxidants from the Thelephora ganbajun mushroom by an ultrasound-assisted extraction technique and evaluation of antiproliferative activity of the extract against human cancer cells. Int J Mol Sci, 17, 1-15.

Yazan LS, Foo JB, Ghafar SAA, et al (2011). Effect of kenaf seed oil from different ways of extraction towards ovarian cancer cells. Food Bioprod Process, 89, 328-32.

Zhang HM, Zhao L, Li H, et al (2014). Research progress on the anticarcinogenic actions and mechanisms of ellagic acid. Cancer Biol Med, 11, 92-100.

\section{(ब) $(\mathbb{8}$}

This work is licensed under a Creative Commons AttributionNon Commercial 4.0 International License. 